\title{
O Design na Comunicação do Patrimônio
}

Design in the Heritage communication

SILVA, Jeferson Luiz Braz da ; Aluno de Graduação; Universidade Federal da Paraíba

jefersonzarb@gmail.com

LEHMKUHL, Luciene ; Professora doutora; Universidade Federal da Paraíba

lucilehmkuhl@hotmail.com

\section{Resumo}

Este artigo apresenta pesquisa pautada no desenvolvimento de projeto de produto de design focado na comunicação do Patrimônio histórico cultural da cidade de Rio Tinto, mais especificamente seu patrimônio material edificado, por meio do desenvolvimento de símbolos gráficos que representem de forma simplificada e de fácil compreensão simbólica e iconográfica. Para o desenvolvimento dos símbolos buscou-se o entendimento das técnicas construtivas de elementos gráficos, por meio de ferramentas digitais e formas de representação física, e ainda, o entendimento do território e seu reconhecimento pelos usuários locais. Foram realizadas atividades de visitação, de observação, de desenho e de criatividade com o objetivo de conhecer e difundir a história e o patrimônio cultural do lugar, instigar e fomentar sua divulgação, assim como subsidiar a elaboração dos próprios símbolos desenvolvidos, que representam parcela significativa do patrimônio da cidade-fábrica na perspectiva de suas edificações.

Palavras Chave: Design; Patrimônio; comunicação e símbolos gráficos.

\begin{abstract}
This article presents a research based on the development of a design product project focused on the communication of the cultural heritage of the city of Rio Tinto, specifically its built material heritage, through the development of graphic symbols that represent in a simplified and easy to understand symbolic way and iconographic. For the development of the symbols we sought to understand the constructive techniques of graphic elements, through digital tools and forms of physical representation, as well as the understanding of the territory and its recognition by local users. Visitation, observation, drawing and creativity activities were carried out with the purpose of knowing and disseminating the history and cultural patrimony of the place, instigating and promoting its dissemination, as well as subsidizing the elaboration of the developed symbols themselves, which represent a significant portion of the capital city of the factory in the perspective of its buildings.
\end{abstract}

Keywords: Design; Communication; Heritage and Graphic symbols. 


\section{Introdução}

O design vem sendo utilizado como meio de valorização e preservação de culturas e patrimônios materiais e imateriais. Considerado como ferramenta multidisciplinar e agente de transformação, ele pode atuar nessa valorização de diferentes maneiras, seja no desenvolvimento de serviços, estratégias, produtos ou demais soluções inerentes à área.

Cada vez mais reconhecido como instrumento estratégico para a valorização de territórios, identidades e produtos locais, assim como a cultura e o patrimônio, "o design apresenta-se como um catalisador da inovação e da criação de uma imagem positiva ligada ao território, a seus produtos e serviços" (KRUCKEN, 2009, p.43).

Manifestando-se em diferentes formas o design pode atuar, com suas metodologias, no desenvolvimento de ações para essa valorização. Krucken (2009) sugere ações essenciais que possam contribuir para a promoção e identificação das potencialidades culturais locais, dentre as quais destacamos o "projeto e desenvolvimento de produtos e serviços diferenciados e com alto valor agregado localmente, com base nos recursos, nas competências disponíveis e na riqueza cultural" (KRUCKEN, 2009, p.51).

A autora apresenta oito ações essenciais para a promoção de produtos e territórios por meio do design:

reconhecer - as qualidades do produto e do território; ativar - as competências situadas no território - no sentido de capacitar ( palestras, workshops...) os atores da produção local; comunicar - o produto e o território; proteger - a identidade local e o patrimônio material e imaterial; apoiar - a produção local; promover - sistemas de produção e de consumo sustentáveis; desenvolver - novos produtos e serviços que respeitem a vocação e valorizem o território; consolidar - redes no território (KRUCKEN, 2009, p.98).

Identificamos nestas ações forte potencial de interação com os projetos de pesquisa realizados no âmbito do Curso de Design da Universidade Federal da Paraíba, especialmente voltados ao desenvolvimento de produtos que poderão atuar na promoção da valorização do patrimônio histórico e cultural da cidade de Rio Tinto. Entretanto, as ações implementadas no projeto demandaram reconhecimento das qualidades da região e consequentemente sua posterior comunicação, podendo também colaborar em ações de proteção deste patrimônio.

Podemos considerar a importância do papel do designer na valorização de territórios e identidades locais ao observar o crescente número de projetos e ações que envolvem a prática do design no desenvolvimento de estratégias e produtos para promover a valorização do território, tanto em seu desenvolvimento direto com a potencialização da economia local por meio da criação de artefatos, quanto na divulgação da região e de sua história, por meio de diferentes plataformas. Adélia Borges, em seu livro Design + Artesanato: o caminho brasileiro, discute os diversos caminhos que o designer pode seguir para valorizar a cultura e patrimônio material e imaterial, apresentando casos e seus resultados no decorrer de sua implantação. (BORGES, 2011, p.57).

A cidade de Rio Tinto, apresenta valores histórico-culturais pouco explorados e pouco preservados pela comunidade e também pela universidade, cujo campus IV encontra-se instalado em parte das edificações da antiga fábrica de tecidos. Rio Tinto é uma cidade-fábrica peculiar, fundada em torno de indústria têxtil, a Companhia de Tecidos Rio Tinto, nas primeiras décadas do século XX pelo Grupo Lundgren. A cidade possui atualmente, expressivo número de edifícios 
provenientes de sua fundação que marcam uma visualidade situada nos detalhes construtivos e ornamentais de suas edificações, especialmente, as erguidas em tijolos aparentes. Vale ainda lembrar sua importante e histórica relação com a indústria têxtil no Brasil e, consequentemente, com o Design produzido para atender demandas de produção da fábrica.

Em leituras sobre o município, encontramos questionamento levantado por Panet sobre a defesa do valor da cidade de Rio Tinto e sua importância enquanto conjunto expressivo e representativo de parte da história da industrialização no Brasil (PANET, 2002, p.61). As reflexões da autora nos levaram a considerar necessário a adoção de um conjunto de ações visando não somente a valorização da cultura material e imaterial do território, como também a preservação, o resgate da memória afetiva e a comunicação, no sentido de não apenas reconhecer, mas tornar público e de conhecimento geral essa valorização. É preciso que estas ações abranjam além da população rio-tintense, a comunidade universitária que movimenta e dinamiza a cidade, sua economia, seu lazer e suas práticas culturais.

\section{Objetivos}

Visando contribuir com ações de valorização e consequente preservação do patrimônio construído da cidade, propomos em projeto de pesquisa, vigente entre 2016 e 2017 ${ }^{1}$, o desenvolvimento de representações visuais por meio da criação de símbolos gráficos a partir dos elementos que compõem as edificações existentes na cidade-fábrica de Rio Tinto, construídas no período de implantação da Companhia de Tecidos Rio Tinto e construção da cidade, especialmente entre os anos de 1918 e 1948.

Para a implementação destes objetivos foram utilizados dados coletados em pesquisas anteriormente realizadas sobre a cidade e a fábrica, sua história e elementos dos marcos arquitetônicos e urbanísticos que contribuíram e contribuem para a caracterização do peculiar patrimônio material da cidade de Rio Tinto. Os resultados obtidos, os símbolos gráficos desenvolvidos a partir de elementos arquitetônicos e decorativos da cidade-fábrica de Rio Tinto, poderão ser aplicados no desenvolvimento de serviços e projetos de produtos em design destinados à valorização do patrimônio histórico/artístico/cultural da cidade e região.

\section{Materiais e Métodos}

Precedendo o início da elaboração dos símbolos foram desenvolvidas atividades que apoiaram a coleta preliminar de dados, além das pesquisas em livros, periódicos, banco de imagens e outras fontes como sites e portfólios. Algumas das atividades, tratadas como oficinas, apoiaram a visualização da percepção das pessoas que estão inseridas no contexto da cidade de Rio Tinto, os usuários desse espaço, acerca dos elementos visuais e arquitetônicos que suscitam maior interesse à representação do patrimônio construído. Atividades de criatividade conduziram ao surgimento de

\footnotetext{
${ }^{1}$ Um produto de design para a Valorização e Comunicação do patrimônio edificado de Rio Tinto, vinculado ao projeto Design e Patrimônio na cidade de Rio Tinto. Bolsista Jeferson Luiz Braz da Silva - PIBIC/UFPB/CNPq (vigência 20162017), orientadora: Professora Luciene Lehmkuhl.
} 
materiais para a ampliação das ações do projeto, tais como oficina de "Cartemas", técnica de criatividade elaborada pelo designer Aloísio Magalhães e Visita Mediada à cidade, suas edificações e monumentos. Foram ainda buscadas referências e projetos similares ao que se desejava como resultado, tanto na proposta de desenvolvimento de símbolos gráficos como a valorização de patrimônios e identidades.

\subsection{Oficina de Cartemas}

Ocorrida no Laboratório de Projeto do Departamento Design, promovida pelo Grupo de Estudos em História do Design e suas conexões, a atividade visou analisar a percepção de moradores e frequentadores da cidade acerca das edificações e seus elementos ornamentais e construtivos, fazendo uso de fotografias. A técnica desenvolvida por Aloísio Magalhães consiste na disposição de cartões postais iguais um ao lado do outro formando elementos visuais únicos a partir de uma só imagem. É uma ferramenta de criatividade e nos possibilitou visualizar os elementos que compõem a cidade fábrica de Rio Tinto em formas diferentes da habitual, proporcionou também pensar esses elementos com outros olhares e pensar as maneiras pelas quais tais elementos podem ser utilizados no desenvolvimento de novos projetos de Design, em produtos, têxteis, superfície e etc.

Figura 1: "Cartema" montado em oficina utilizando fotografias.

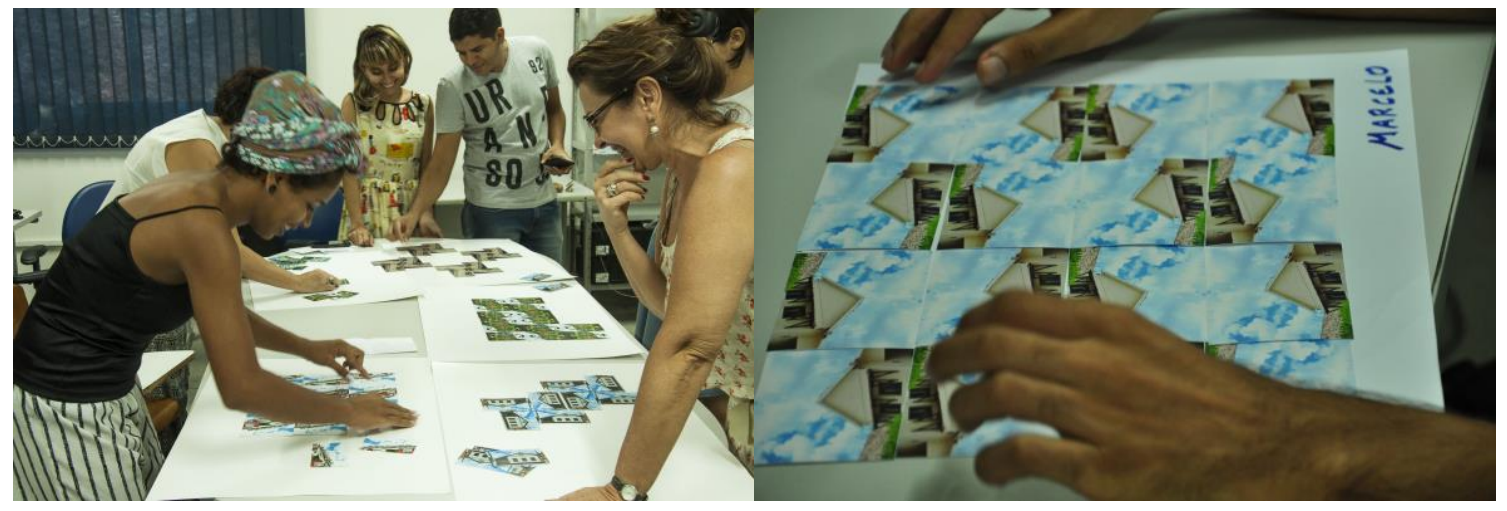

Fonte: Jeferson Luiz Braz da Silva, 2017.

\subsection{Visita Mediada à Cidade-Fábrica de Rio Tinto}

A atividade, intitula "Visita Mediada à cidade-fábrica de Rio Tinto", consiste numa apresentação do contexto histórico da cidade feita in loco, auxiliada por um guia prático, em formato de mapa, elaborado em projeto de pesquisa intitulado: Referências Urbanas de Rio Tinto para o desenvolvimento de Projetos de Produtos em Design, coordenado pela Professora Doutora Luciene Lehmkuhl e executado pelo aluno/bolsista Jeferson Luiz Braz da Silva, como PIBIC/UFPB/CNPq, vigência 2015/2016. Durante a visita, caminhando pela cidade, procura-se identificar as edificações por meio de legendas apresentadas no mapa, como casas, chalés, edificações em ruínas e edificações em tijolos aparentes ou não. Após explanar sobre a cidade, suas características e momentos importantes de sua construção, já ao final da atividade é solicitado que 
cada participante elabore desenhos de observação e/ou livre a partir das edificações, seus respectivos detalhes construtivos e ornamentais que mais tenham chamado atenção durante o percurso. Os desenhos elaborados a partir da atividade proposta auxiliaram a identificação das edificações e detalhes arquitetônicos considerados mais relevantes. Dentre os desenhos realizados, os elementos que mais se repetiram foram os vitrais das janelas da igreja, assim como as figuras da águia e da lira presentes na fachada principal da igreja. Como elementos ornamentais e detalhes arquitetônicos, os maiores destaques se referem às edificações da Igreja Santa Rita de Cássia e do Cineteatro Orion, sendo os elementos destas duas edificações que se tornaram fundamentais no desenvolvimento do projeto.

Figura 2: Guia Prático da Cidade e Desenhos elaborados durante a atividade.
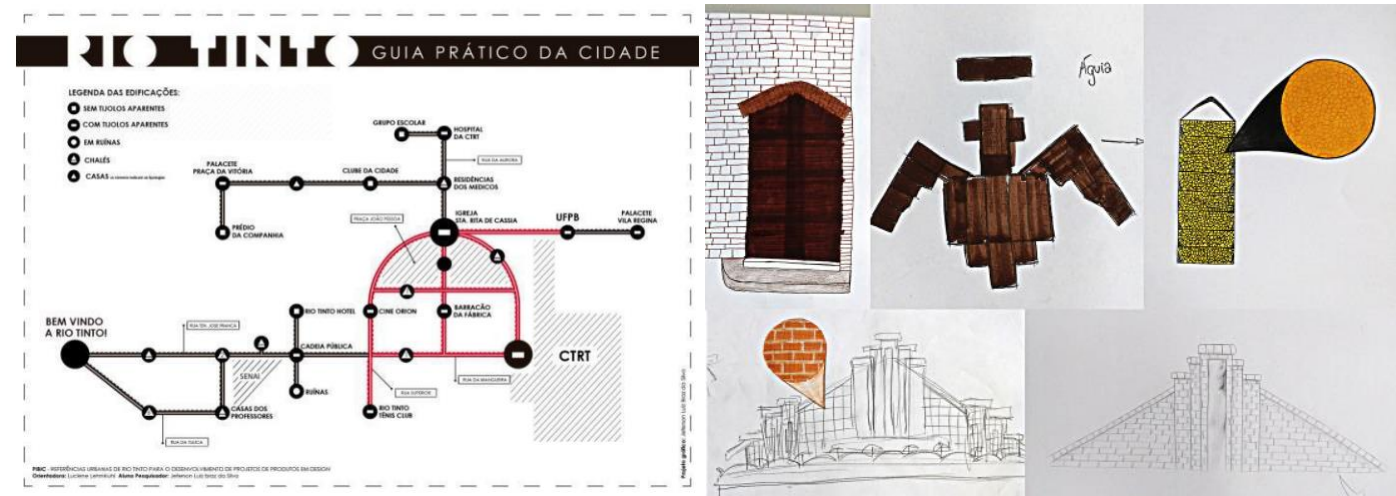

Fonte: Jeferson Luiz Braz da Silva, 2017.

\subsection{Projetos Similares}

Foram pesquisados projetos de design que fomentassem a valorização do patrimônio histórico cultural, material ou imaterial. Encontrados os projetos foi feito um resumo explicitando seus desenvolvedores, a finalidade do projeto e sua demanda, em alguns casos financiados por órgãos de fomento. Os projetos pesquisados têm finalidades próximas: representar graficamente artefatos característicos de uma localidade para sua comunicação. Destacamos a participação dos atores locais, evidenciada no projeto Superfícies da Cidade, que apresenta um caminho para a valorização do território que não apenas insere a observação de um agente externo, mas conta com a ação de quem vivência o contexto. Seus desdobramentos vão desde materiais gráficos impressos à superfície de produtos industriais e têxteis.

Na superfície da Cidade - Projeto de extensão realizado no Curso de Design da Universidade Federal de Minas Gerais e coordenado pela Prof. Maria Luiza Dias Viana. O projeto é a expansão do campo do design de superfície para o do território, desenvolveu padronagens a partir de técnicas de criação e repetição que representam o território a partir do envolvimento de moradores do território por meio de oficinas. (VIANA, 2015)

Dingbat Brasília - Desenvolvido pelo escritório de design Grande Circular, a partir de demanda do Centro Cultural Banco do Brasil e Correio Brasiliense, o projeto consiste também no desenvolvimento de uma fonte digital que representa de forma simplificada os elementos iconográficos da capital brasileira. (GRANDE CIRCULAR, 2016) 
Mini Rio - A partir de demanda pessoal, o Designer carioca Fábio Lopes desenvolveu o projeto que tem como objetivo representar a cultura material e imaterial da cidade do Rio de Janeiro, abarcando elementos construídos como o hotel Copacabana Palace e manifestações culturais como o carnaval suburbano. (LOPEZ, 2016)

Urbano Ornamento - Projeto desenvolvido pela Arquiteta Fernanda Guimarães Goulart em sua tese de doutorado, consiste no inventário de gradis ornamentais da cidade de Belo Horizonte representados graficamente, por meio da vetorização de suas formas. (GOULART, 2012)

Portas de Copa - Projeto desenvolvido pela arquiteta Cássia Mota, com apoio do Financiamento coletivo Benfeitoria. O projeto retrata algumas portas de edificações existentes no bairro de Copacabana, Rio de Janeiro, por meio de vetorização de seus elementos, grades e ornamentos. (MOTA, 2015)

Iconografia de Caminhões de Pernambuco - Desenvolvido pelos Designers Fátima Finizola e Damião Santana e com incentivo do Fundo Pernambucano de Incentivo à Cultura - FUNCULTURA, consistiu no registro de elementos visuais decorativos das carrocerias de caminhões que circulam no Estado de Pernambuco por meio da criação de fonte digital iconográfica de tipo Dingbat. (FINIZOLA, et al. 2012)

Ding Bat Cobogó - Desenvolvido pelo Designer Pernambucano Guilheme Luigi, é uma fonte digital de tipo DingBat que representa os Cobogós Pernambucanos e teve apoio do Fundo Pernambucano de Incentivo à Cultura - FUNCULTURA. (LUIGI, 2013)

Grande Vitorinha - Projeto tipográfico/iconográfico desenvolvido pelo Locomotipo, uma oficina de Design e Arte de Vitória, no Espírito Santo, com apoio do FUNCULTURA e do Governo do Estado, o qual consistiu no desenvolvimento de fonte do tipo Dingbat representando graficamente elementos culturais e arquitetônicos presentes na cidade de Vitória. (LOCOMOTIPO, 2016)

Dingbat Ladrilho Hidráulico - Projeto desenvolvido também pelo designer Pernambucano Guilherme Luigi e com apoio do Fundo Pernambucano de Incentivo à Cultura - FUNCULTURA e o Governo do Estado de Pernambuco. Foram desenvolvidos a partir da síntese de 62 artefatos a fonte digital representando os grafismos e desenhos dos ladrilhos encontrados em diversos locais no Estado de Pernambuco. (LUIGI, 2016)

Dingbat Gradil - Desenvolvida como trabalho de conclusão do curso de Design Gráfico no Instituto Federal da Paraíba, pelo designer Hossein Albert Cortez que catalogou exemplares de gradis localizados na cidade de João Pessoa e os sintetizou em representações gráficas criando a fonte digital do tipo Dingbat. (CORTEZ, 2014)

\section{Resultados}

O processo de design está atrelado a um conjunto de múltiplas possibilidades, que visa estabelecer o ponto de partida e demais ações no decorrer da implementação do projeto. Segundo Rodolfo Fuentes na implementação de um método de design, este não deve ser tomado como única possibilidade, admitindo-se a existência de múltiplos caminhos, a partir do conceito de que os métodos são "simplesmente ferramentas na bagagem multidisciplinar dos designers" (FUENTES, 2006, p.27). 
Diversos autores apresentam métodos que podem ser utilizados simultaneamente, buscando adequações de acordo com as necessidades do projeto e sugerindo, para fins didáticos e aplicações práticas, a divisão das ações propostas em fases distintas, com o interesse de agrupar as necessidades mais próximas e servir para a projetação como forma de "guia". Bernd Löbach apesar de sugerir que essa divisão seja feita em quatro fases diferentes: Análise do Problema, Solução do problema, Valoração das soluções e Implementação da solução, salienta a importância da compreensão de que as fases sejam apenas elucidativas, uma vez que na prática projetual não se pode exatamente separá-las, "elas se entrelaçam umas às outras, com avanços e retrocessos" (LÖBACH, 2001, p.141). Este autor também enfatiza a relação entre as funções do produto, lançando especial atenção à função estética e sua relação com a função simbólica no desenvolvimento de projetos, cujo centro de interesse estaria focado nas necessidades do usuário, aspectos de interesse ao trabalho aqui desenvolvido (LÖBACH, 2001, p.57).

Para o desenvolvimento da coleção de símbolos gráficos, proposta como resultado final da pesquisa realizada, foram adotados, como guia para projetação os ciclos sugeridos por Lobach (2001 p.142) que contam com apoio de etapas servindo como norteamento projetual. Inicialmente, durante a etapa analítica, propôs-se identificar, coletar e refletir a partir de dados textuais e imagens, acerca dos elementos construtivos, estruturais e ornamentais, que compõem a tipologia arquitetônica e urbanística da cidade de Rio Tinto. Foram também feitas na primeira etapa junto à análise dos dados, a identificação dos principais elementos que compõem as edificações, separando-os por categorias, sejam elas funcionais, formais, dimensionais e materiais, dentre outras, com a finalidade de otimizar a posterior produção dos símbolos.

$\mathrm{Na}$ etapa criativa, alternativas foram geradas para o estudo das implicações do projeto, para o estudo e análise das formas, escolha de uma ideia, formalização da mesma e sua verificação. Para a construção dos símbolos foram utilizados princípios da Gestalt, ou "Leis da Gestalt" teoria a qual destaca o Arquiteto e Designer argentino Guilhermo González Ruiz, como sendo "uma das matrizes do pensamento do Design, podendo ser aprendido e ensinado a partir do princípio de que não percebemos as coisas como elementos desconexos, mas as organizamos através do processo perceptivo, em conjuntos significativos" (GONZÁLEZ RUIZ, 1994, p. 17, tradução nossa). ${ }^{2}$ e como destaca Rudolf Arnheim, psicólogo e pesquisador em psicologia da forma:

ao olhar para um objeto nós procuramos alcançá-lo. Com um dedo invisível movemo-nos através do espaço que nos circunda, transportamo-nos para lugares distantes onde as coisas se encontram, tocamos, agarramos, esquadrinhamos suas superfícies, traçamos seus contornos, exploramos suas texturas. O ato de perceber formas é uma ocupação eminentemente ativa (ARNHEIM, 2005 p. 36)

Como parte da terceira etapa, foram feitas avaliações das alternativas geradas e em relação aos estudos formais, foram analisados os comportamentos das espessuras das linhas, dimensões dos desenhos elaborados e demais avaliações para que o produto final tenha bom acabamento e seja de fácil percepção em diferentes plataformas, digitais ou físicas. Após a definição dos elementos constitutivos, foram elaborados objetos digitais por meio de ferramenta vetorial, o software Adobe Illustrator.

Foram, ao todo, elaborados vinte e três (23) símbolos gráficos, sendo doze (12) deles representando fachadas das edificações consideradas importantes e as mais recorrentes nos desenhos das atividades elaboradas durante as fases da pesquisa, como a Igreja Santa Rita de Cássia, 
O Cineteatro Orion, o Barracão da Fábrica e as Ruínas dentre outras. Os outros dez elementos são ornamentos, janelas e demais figuras presentes nessas fachadas e que mereceram destaque por se tornarem diferenciais entre as edificações, principalmente aqueles localizados na Igreja como a águia e a lira.

Para a etapa final, construção dos símbolos principais referentes às fachadas das edificações, foram utilizados espessura linear em dois níveis, 2X para os contornos principais e $1 \mathrm{X}$ para detalhes, a fim de se manter unidade e para que pudessem ser reproduzidos em meio digital ou em impressos sem danificar sua estrutura. Foram, de maneira geral, utilizadas apenas linhas retas com cantos arredondados e angulações das mesmas para se obter os telhados das edificações. Os símbolos resultantes da ampliação de detalhes, como janelas e ornamentos, foram elaborados de forma semelhante, porém em linguagem diferente, para evitar o uso de linhas finas ou grossas demais e assim manter também uma unidade.

A não utilização do Grid para a construção permitiu a representação mais livre dos objetos, que continuaram atendendo as especificações determinadas de linhas retas e espessuras em três variantes, possibilitando a ampliação dos elementos que mantiveram padrões regulares de visualidade, clareza, eficiência e identidade.

Figura 3: Indicação das linhas e suas espessuras dentro do objeto desenvolvido.

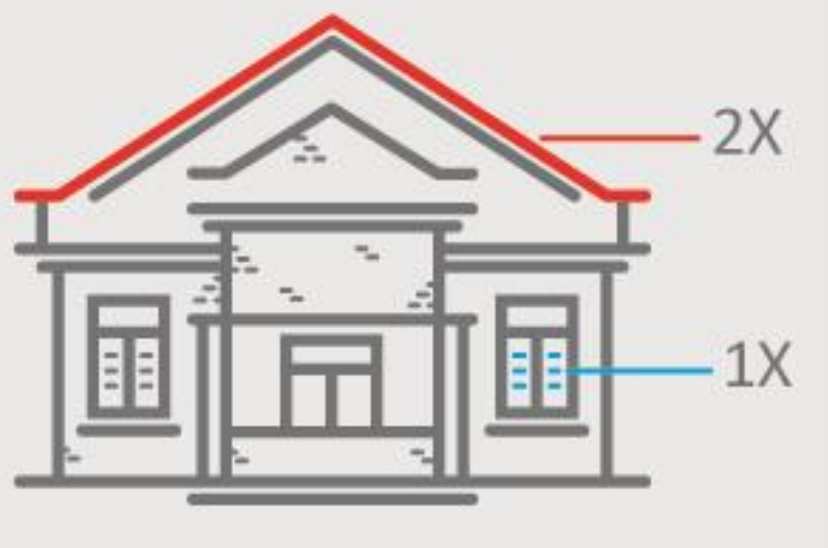

Fonte: Jeferson Luiz Braz da Silva , 2017. 
Figura 4 - Cineteatro Orion e seu respectivo símbolo.
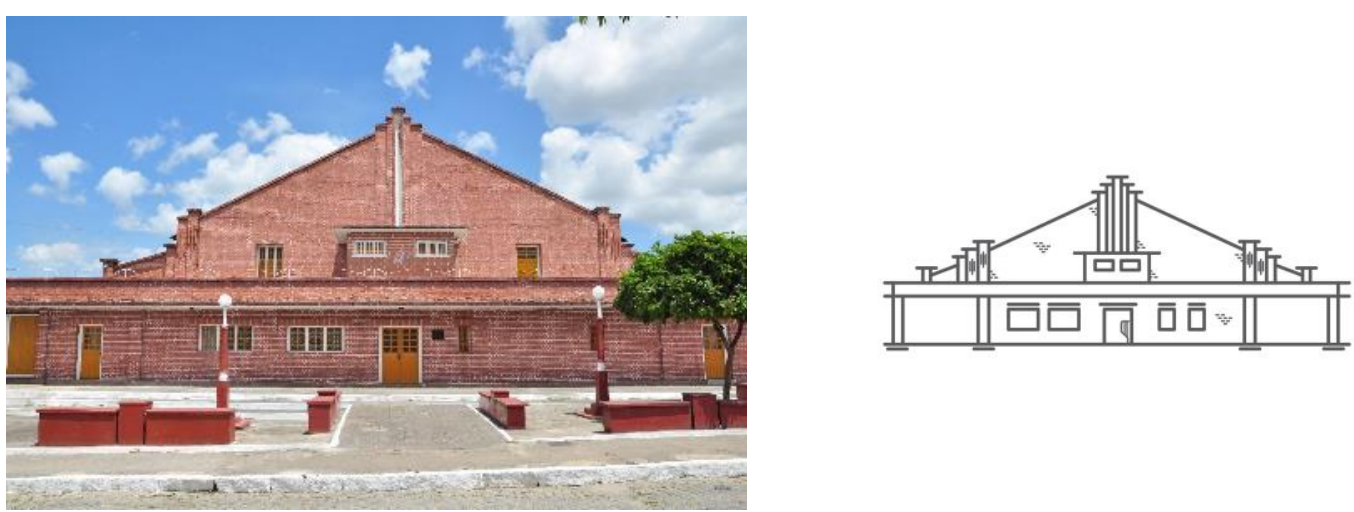

Fonte: Jeferson Luiz Braz da Silva , 2017.

Figura 5 - Igreja Santa Rita de Cássia e seu respectivo símbolo e representação dos detalhes.
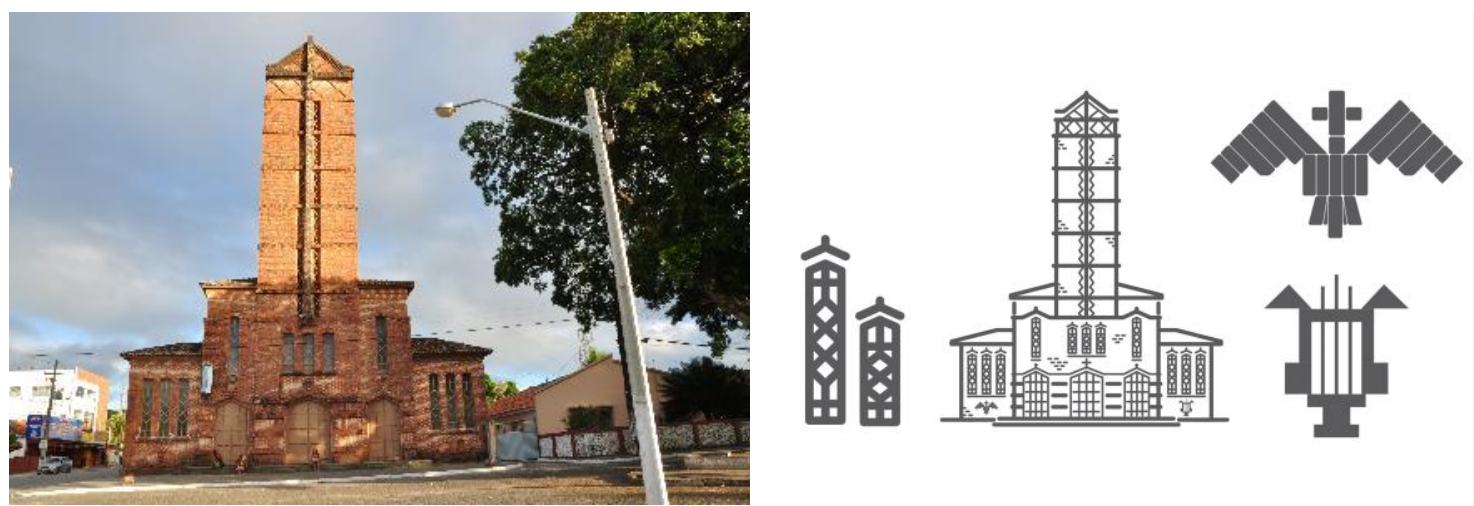

Fonte: Jeferson Luiz Braz da Silva, 2017.

Figura 6 - Antigo prédio da Hospedaria Rio Tinto e seu respectivo símbolo.
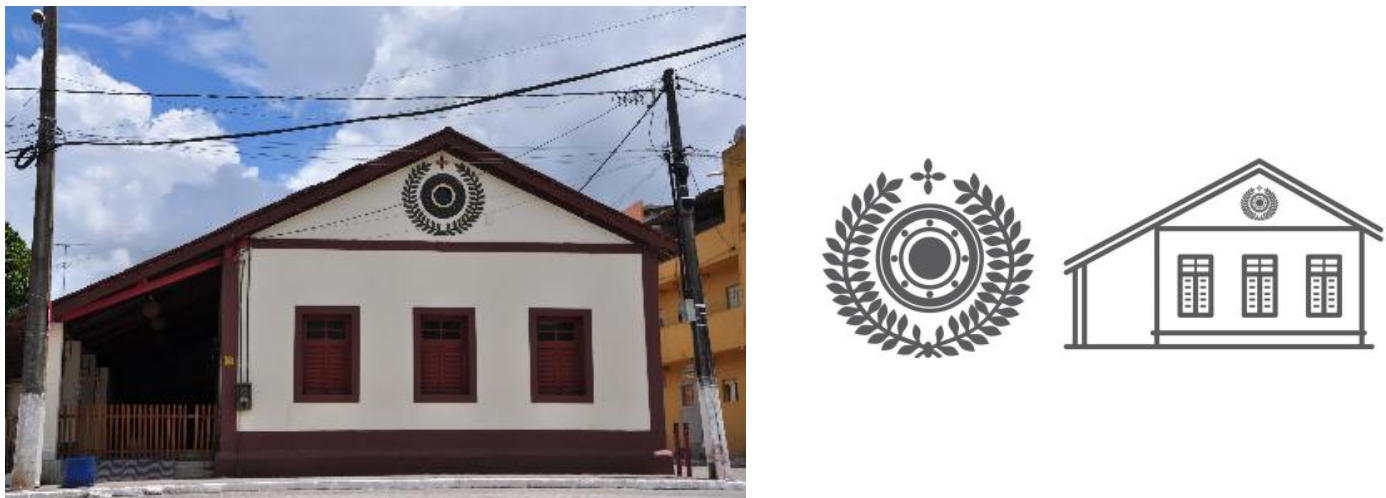

Fonte: Jeferson Luiz Braz da Silva, 2017. 
Figura 7 - Cadeia Pública da Cidade de Rio Tinto e seu respectivo símbolo.
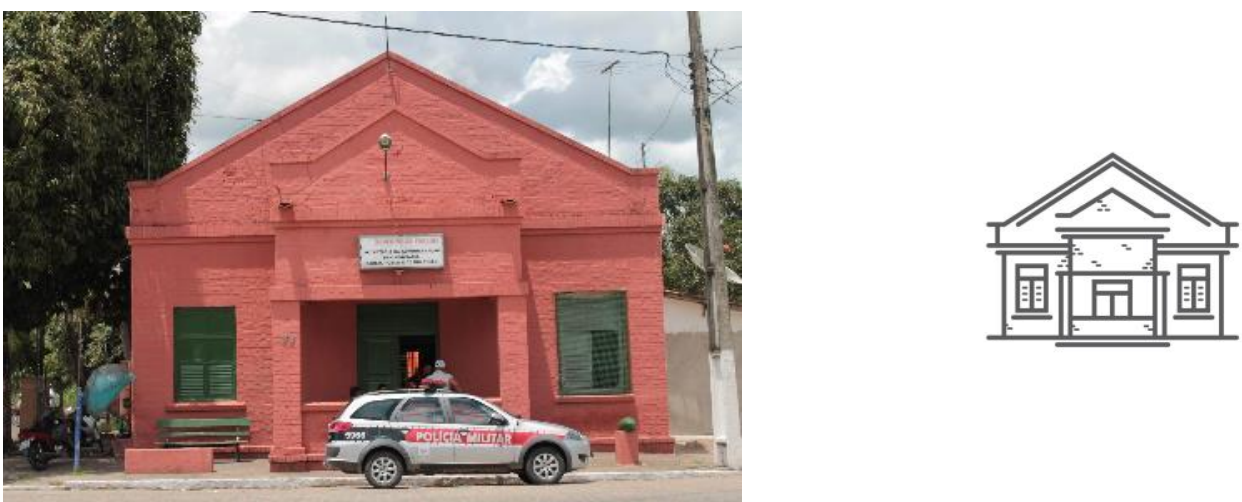

Fonte: Jeferson Luiz Braz da Silva, 2017.

Figura 8 - Símbolos desenvolvidos durante a pesquisa. Na sequência: Cineteatro Orion, Igreja Santa Rita de Cássia, Barracão da Fábrica, Cadeia Pública da cidade, Ponte, Tipo de Chalés localizados na Praça João Pessoa, Ruínas de edificações da Fábrica, Prédio da Antiga Hospedaria Rio Tinto, Rio Tinto Tênis Club, Casas de Tipologia 1, Palacete Lundgren Tipo de Chalés, Grupo Escolar Herman Lundgren, Lira (Detalhe da Igreja), Águia (Detalhe da Igreja), Vitrais da Igreja, Cobogós do Tênis Club, Porta da Tênis Club, Janelas, Janela do Palacete Lundgren, Detalhe ornamental da Hospedaria Rio Tinto e Letreiro Art Decó do Rio Tinto Tênis Club.
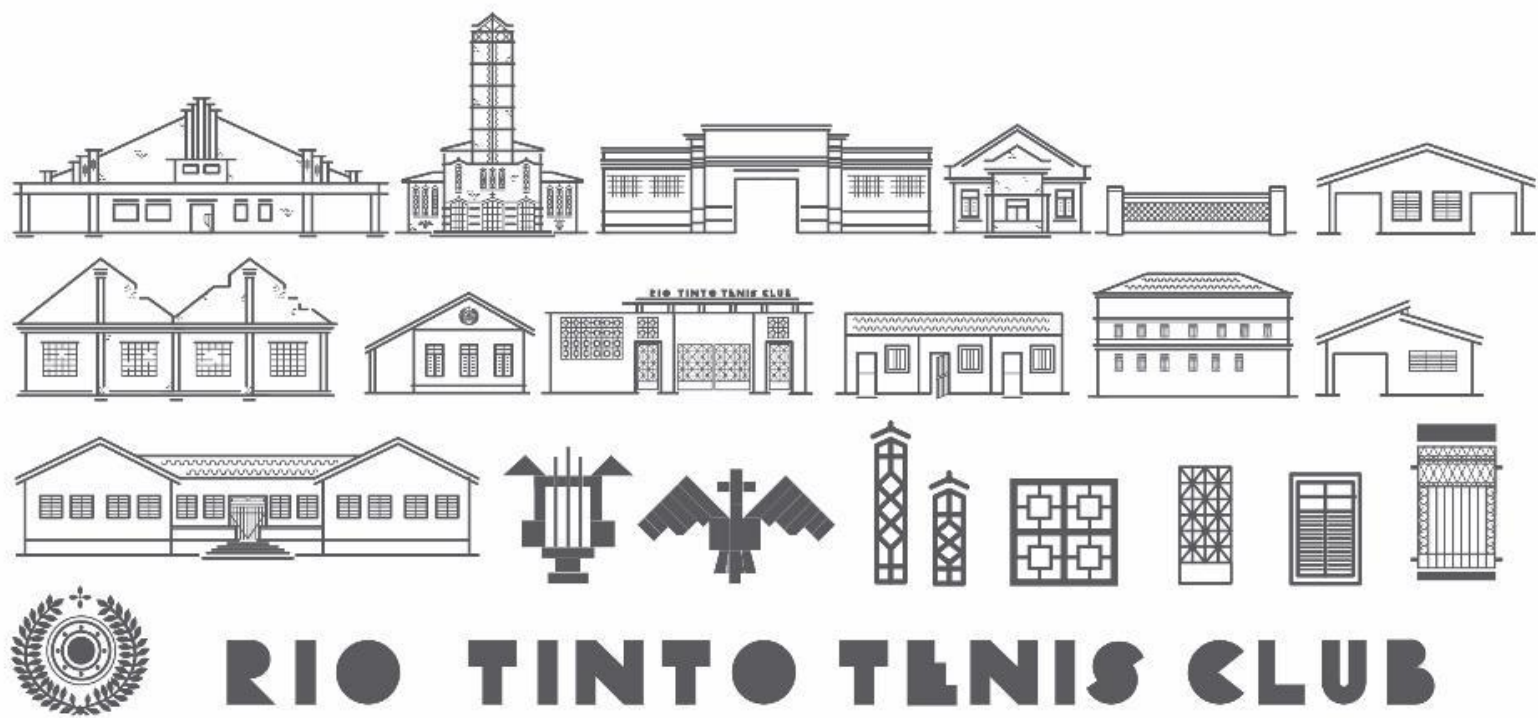

Fonte: Jeferson Luiz Braz da Silva, 2017.

\section{Considerações Finais}

A pesquisa concluiu-se com o desenvolvimento de 22 símbolos gráficos, dentre fachadas, detalhes e ornamentos das edificações. Elaborados com a utilização de linhas retas com duas diferentes espessuras, os símbolos foram elaborados por meio de software de vetorização digital. 
Os símbolos gráficos resultantes desta pesquisa servirão para a comunicação do patrimônio edificado da cidade de Rio Tinto e poderão ser utilizados de diferentes maneiras, incluindo sua aplicação em projetos de design ou demais áreas que trabalhem com a iconografia ou visualidade presentes no objeto proposto. Pretende-se a partir desses símbolos o desenvolvimento de novos elementos gráficos para a representação do patrimônio material e imaterial local, contribuindo para a preservação da memória dos elementos inseridos no contexto urbano da cidade de Rio Tinto. Como sugestão de aplicação foi criado um conjunto de quatro selos, por meio das premissas do Design Filatélico, para apresentação dos resultados dessa pesquisa em um produto de design que poderia facilmente ser implementado no mercado. A figura de número 9 apresenta estes selos.

Figura 9 - Conjunto de selos.

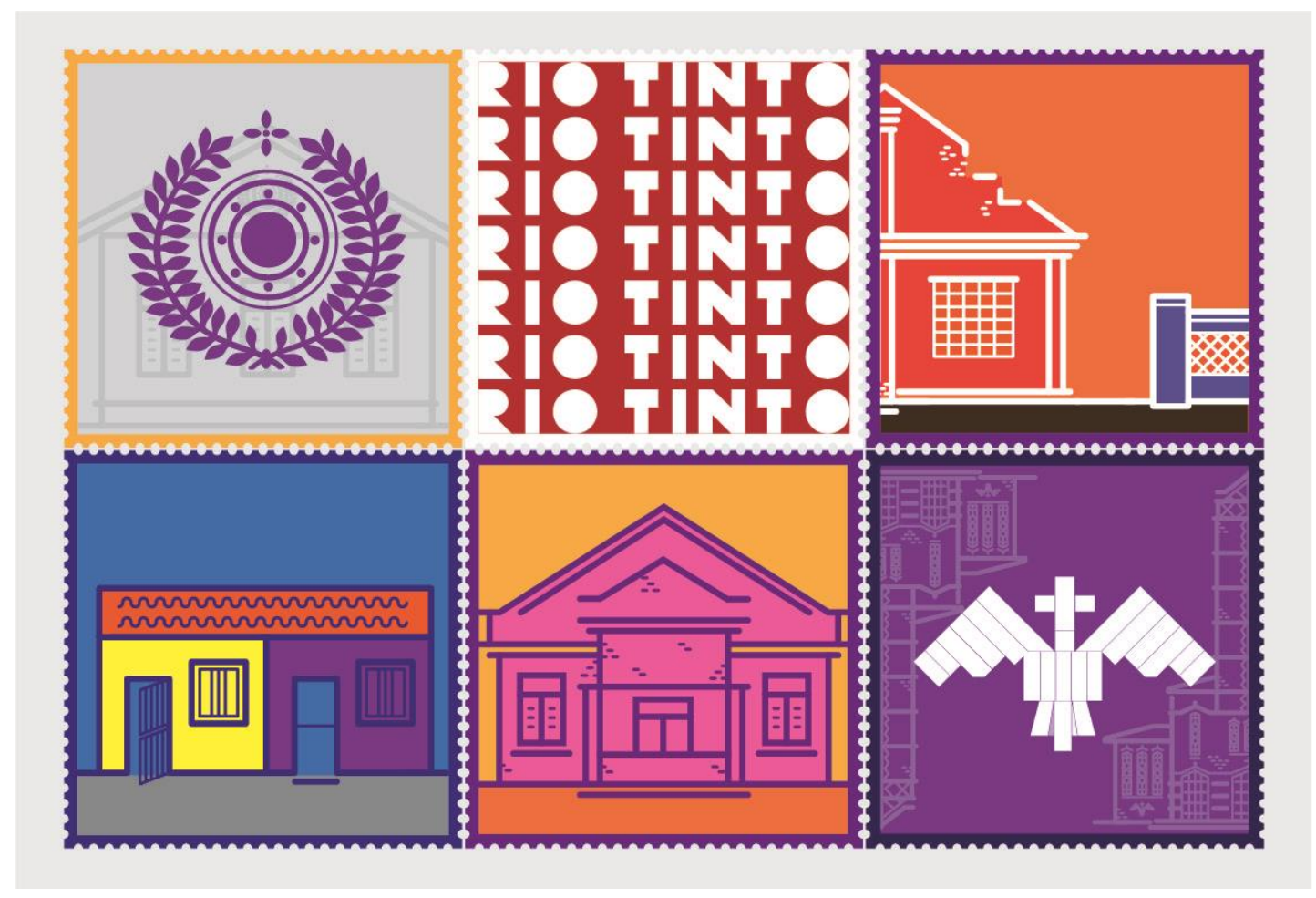

Fonte: Jeferson Luiz Braz da Silva, 2017.

\section{Referências}

ARNHEIM, Rudolf. Arte e Percepção Visual: uma psicologia da visão criadora. São Paulo: Pioneira Thomson Learning, 2005.

BORGES, Adélia. Design + Artesanato: o caminho brasileiro. São Paulo: Editora Terceiro, 2011.

CORTEZ, Hossein Albert. Dingbat Gradil. Disponível em: < https://www.behance.net/gallery/18043123/Dingbat-Gradil > Acesso em: 02/05/2017.

FINIZOLA, F.; SANTANA, D. Iconografia das Carrocerias de Caminhão de Pernambuco. Disponível em: < www.designvernacular.com.br/carrocerias>. Acesso em 30/02/2017. 
FUENTES, Rodolfo. A prática do design gráfico: uma metodologia criativa. São Paulo: Edições Rosari, 2006.

GONZÁLEZ RUIZ, Guilhermo. Estudio de Diseño: sobre la construcción de las ideas y su aplicación a la realidad. Argentina: Editorial EMECE, 1994.

GOULART, Fernanda Guimarães. Urbano Ornamento: um inventário de grades ornamentais de Belo Horizonte (e outras belezas). Tese de Doutorado, Universidade Federal de Minas Gerais. Belo Horizonte, 2014.

GRANDE CIRCULAR. Dingbat Brasília. Disponível em: < http://www.grandecircular.com/trabalho/dingbats-brasilia/> Acesso em: 15/05/2016.

KRUCKEN, Lia. Design e Território: valorização de identidades e produtos locais. São Paulo: Studio Nobel, 2009.

LÖBACH, Bernd. Design Industrial: bases para a configuração dos produtos industriais. Tradução Freddy Van Camp. 1. ed. São Paulo: Edgard Blücher, 2001.

LOCOMOTIPO. Grande Vitorinha. Disponível em: <www.grandevitorinha.com.br> Acesso em: 15/10/2016.

LOPEZ, Fábio. Mini Rio. Disponível em: <http://www.minirio.com.br/> Acesso em: 28/04/2017.

LUIGI, Guilherme. Dingbat Ladrilho Hidráulico. Disponível em: <http://www.dingbatladrilho.com.br/> Acesso em 02/05/2017.

Dingbat Cobogó. Disponível em: <https://www.be.net/gallery/11202187/Dingbat-

Cobogo> Acesso em: 28/04/2017.

MAGALHÃES, Aloisio. Cartemas: a fotografia como suporte de criação. Rio de Janeiro: Edições Funarte, 1982. (Catálogo da exposição realizada na Galeria de Fotografia da Funarte, 5 nov. a 3 dez. 1982).

PANET, Amélia; et al. Rio Tinto: estrutura urbana, trabalho e cotidiano. João Pessoa: UNIPÊ Editora, 2002.

VIANA, Maria Luiza Dias; et Al. Na Superfície da Cidade. Disponível em:< https://www.behance.net/gallery/33485933/Na-Superficie-da-Cidade> Acesso em: 28/04/2017.

MOTA, Cássia. Portas de Copa. Disponível em: <http://portasdecopa.com/> Acesso em: 28/04/2017. 